\title{
BACK TO BASICS: LEARNING ABOUT EMPLOYEE ENERGY AND MOTIVATION FROM RUNNING ON MY TREADMILL
}

\section{Theresa M. Welbourne, Steven B. Andrews, and Alice O. Andrews}

In an effort to understand how to optimize employee energy at work, we borrow from the sports physiology literature to develop and test several concepts that have now been used in more than 75 large and small organizations (e.g., automobile firms, banks, hospitals, manufacturing, high technology, service businesses, financial services, and more). Our focus on employee energy led us to develop new measures and processes for our research. The resulting studies presented in this article test two hypotheses focusing on the link between employee energy, turnover, job performance, and job satisfaction. Consistent with what we know about athletic performance, we found that energy is an optimization construct and that variation in employee energy at work has detrimental consequences for performance and satisfaction. (C) 2005 Wiley Periodicals, Inc.

The concept of human motivation is at the core of any management-related discipline (e.g., human resource management, organization behavior, strategy, organization theory). The importance of this topic is attested to by the vast accumulation of research in this area. Fascination with the subject is based on the long-held assumption that more motivation leads to better performance, and, therefore, if we can understand what motivation is, how it is formed, and how to increase it, we can use that knowledge to enhance individual and firm performance (Lawler, 1973). Yet, despite decades of research and theorizing, the concept of motivation in the organization remains contested. Hundreds of definitions exist (Landy \& Becker, 1987), numerous theories have been presented to ex- plain motivation (Ambrose \& Kulik, 1999), and consistent measurement of the construct has suffered as a result (Pinder, 1984). Indeed, Ambrose and Kulik (1999) suggested that researchers have shied away from trying to define motivation at all. Given the critical role motivation plays in organizational studies, and how important motivation is becoming today, we make one more attempt at re-evaluating the concept of motivation but from a somewhat different perspective. We hope our novel approach not only adds to what we currently know about motivation, but also helps bring the topic even further into the forefront of managing businesses.

At the core of our argument is the assumption that motivation at work is really

Correspondence to: Theresa M. Welbourne, University of Michigan Business School, Executive Education, 724

East University, Suite 3700, Ann Arbor, MI 48109-1234, twelbour@umich.edu or Theresa@eepulse.com

Human Resource Management, Spring 2005, Vol. 44, No. 1, Pp. 55-66

(C) 2005 Wiley Periodicals, Inc. Published online in Wiley InterScience (www.interscience.wiley.com).

DOI: $10.1002 / \mathrm{hrm} .20040$ 
...one key difference between sports physiology and the management motivation theories is that within the sports literature, more motivation or more human energy is not always better. about employee energy, and although energy can be directed toward many efforts (e.g., relaxation, sports, homework, etc.), we study energy exerted at work. Given our interest in motivation, and our belief that human energy is at the core of motivation at work, we sought to explore ways human energy has been studied in nonwork settings. Our goal was to see if we could transfer learning from nonwork disciplines in a way that would help us find a new approach to studying motivation. As a result of this search, we found extensive literature in sports physiology that specifically describes and assesses human energy directed at optimization of performance (in both its physical and mental aspects). In reviewing this literature, we came to the conclusion that one key difference between sports physiology and the management motivation theories is that within the sports literature, more motivation or more human energy is not always better. In fact, the sports literature would suggest that athletes or anyone attempting to maximize bodily energy should find the level of exertion that is best for that individual (given factors like age, overall physical health, etc.) and then minimize variance around this target. ${ }^{1}$ In other words, energy is something that should be optimized, not maximized. If we generalize to other examples of energy, we see many arenas where more energy is not always better.

For example, delivering higher levels of energy to a light bulb will not make it brighter; instead, more energy will make the bulb explode. The field of quality management made great strides in helping organizations improve performance and quality by teaching businesses how to find an optimal level of machinery output and then minimize variance in the output level. It is the minimization of variance that drives out error.

The same concept of optimization versus maximization is true for human beings. Too much motivation or energy can lead to detriments in long-term performance, as is poignantly captured in the Japanese phenomenon of karo-jisatsu (death through overwork). Even though we know that more energy is not always better, many well-established theories of motivation deemphasize this insight.

\section{Athletic Performance and Motivation}

Since the riddle of employee motivation has plagued management researchers looking at the issue, scientists have begun to look elsewhere to find answers. A similar question faces those who strive to be top athletes or even to enter into a systematic exercise program designed to optimize bodily energy use (i.e., consume calories, help the individual feel better, and raise overall health). The assumption that more is better was, for many years, adopted by athletes, but recent research suggests that the human body does best under a different set of conditions.

Performing at the outer bounds of human capabilities requires not only the genetic gift of innate skills, but long hours of training as well. As the many popular tales, stories, or movies about athletes attest, staying focused and motivated during this intense and often emotionally painful period may be the toughest problem for the athlete to overcome. However, the process can seem much the same even for someone who is not of Olympic quality. Therefore, it may make sense to see how athletic trainers and sports physiologists have struggled to overcome this stumbling block. ${ }^{2}$

Ideas about sports behavior have been applied to business practice before. But writers in this tradition mainly borrow from the sports psychology literature (cf. Perry \& Jamison, 1997), sports strategy literature (cf. Gilbert \& Jamison, 1994; Leifer, 1988; Rosenbaum, 1979), or sports coaching literature (cf. Hargrove, 1995; Kinlaw, 1999; Shula, Blanchard, \& Cruderman, 1995), rather than the sports physiology literature. Such writers either strive to create top-flight managerial performance by incorporating the athletic mind-set into the workplace or to enhance employee performance by enlightening the manager about the secrets of successful athletic coaching.

Sports physiologists now realize that the human body can only perform at its peak level for a short period of time (on the order of a few months). Therefore, it is necessary to periodicize training regimens and, as a result, the way in which energy is being exerted (Burfoot, 1997; Glover \& Glover, 1999; 
Noakes, 1991). This approach to motivation (energy exertion) and training proceeds in stages, peaking for certain key events. For example, runners with high-performance goals will first build a strong aerobic base. Building on this base, high-intensity workouts are then used to increase, or sharpen, strength and speed. Although these are objectively tougher workouts, they should not feel that much tougher subjectively. This workout schedule should lead to dramatic increases in performance, which, if timed correctly, peaks at the primary event for which one is training. But to ensure a strong performance at a given event, athletes taper (recover) for a short period of time prior to the race by reducing the overall volume of training. This effort is followed by a more intense period of recovery (during which training still feels somewhat hard as the body recuperates from the previous stresses it faced), and the process is repeated as necessary. Although there is a long-period cycle, there should be little variation in perceived effort in any short time frame.

So it is obvious there are two forms of variation in training. One, which is beneficial, is to vary the routines and purposes of the training schedule. The other, which is detrimental, is variation in perceived effort. As the aching bodies of "weekend warriors" can attest, the human body does not handle such variation well. Consider the plight of the nonathlete trying to optimize an exercise routine. The first thing that is done upon entry to any professionally run health club or gym is to determine an optimal workout program for someone. The target heart rate is calculated, and the after-work athlete is taught how to exercise while maintaining a level of work that is within his/her zone (target heart rate zone).

One technique trainers use to advise athletes to avoid overtraining is the use of perceived effort scales. The walls of health clubs often are adorned with depictions of such scales. Though many such scales are numeric, others use faces to assist the rating process. Generally, a person rates the workout on a scale from very easy to overly difficult, with the goal being to stay in a middle zone where the workout is tough but not ex- hausting. Overtraining leads to injury and burnout, diminishing the athlete's motivation. Similarly, we argue that perceived energy exertion at work should be roughly constant (low variation) for higher performance. Consistently bouncing from being underworked to being overworked and back will decrease the motivation and effectiveness of the employee.

There are two ways one can examine performance. The first is to look at the performance of the worker as a manager might view him/her. Such a performance metric focuses on how well the employee is performing, with an emphasis on the short term. But an employee might be performing at acceptable levels while planning on leaving the organization because of the demands of the job. Focusing on voluntary termination allows us a more behavioral marker of longterm performance and potential costs to the organization.

Hypothesis 1: As variation in employee energy at work increases, long-term performance will decrease.

A measure of employee energy contextualizes the perceptions one has of the work environment. How hard one is working, how challenging one's work is, and how efficiently that work is getting done are all relative to the subjective sense of one's capacities and abilities at a given moment. We can push this further, though. How one feels about the effort one is exerting should be shaped by how one feels about one's job. Although the pace and efficiency of work should shape energy level, we suggest the satisfaction one has with one's effort will be associated with the variation in employee energy. This works both ways: The more satisfied one is with work, the less one's energy should vary, and the less one's energy varies, the more satisfied one will tend to be with work. This should be true regardless of the level of the energy one has-one may be more satisfied with one's job whether one is working hard or easy as long as the demands are roughly constant.

In a sense, this is analogous to an athlete who has entered the "flow" (Csikszent-
Overtraining leads to injury and burnout, diminishing the athlete's motivation. Similarly, we argue that perceived energy exertion at work should be roughly constant (low variation) for higher performance. Consistently bouncing from being underworked to being overworked and back will decrease the motivation and effectiveness of the employee. 
...satisfaction with the work experience may be most likely to occur when the match between the sense of one's abilities and the tasks asked of one match on a consistent basis over time. Constantly wavering between being underchallenged and overchallenged will likely lower satisfaction. mihalyi, 1991), or what Perry and Jamison (1997) call "the Zone." At this point, the challenges facing the athlete match the abilities $s /$ he brings to the activity, such that the activity demands full focus and a high level of energy. This combination leads to an increased chance for success and, more important, a stronger sense of satisfaction with the activity and its outcome. An elite marathoner and the average jogger may both reach this state, albeit at a vastly different pace. In a similar manner, satisfaction with the work experience may be most likely to occur when the match between the sense of one's abilities and the tasks asked of one match on a consistent basis over time. Constantly wavering between being underchallenged and overchallenged will likely lower satisfaction. On the other hand, dissatisfaction with one's abilities makes flow much less likely to occur, increasing the sense that one's work experience is out of control, and thereby increasing the variation in the reported energy level.

Hypothesis 2: Variation in the employee energy level will be negatively associated with job satisfaction.

\section{Methods}

The measure of employee energy at work ${ }^{3}$ that we employ in our research was used in two prior studies (Welbourne, 1997; Welbourne \& Felton, 1998). The question asked of employees on a weekly basis uses a 0 to 10 scale, which reads in ways that are parallel to sports language. The first few companies to use this metric were high-technology firms on the West and East Coasts. They were looking for a more marketing-related way to "sell" the process internally, and as a result, the term Pulse was coined. In addition to the overall process and measure being called Pulse, labels were borrowed from sports to describe the scale. The low end of the scale (from 0 to 2.4) is called the "at rest" zone, and in this area employees report they are not doing much, do not feel energized by their work, and are generally not very satisfied with being in this state. The next range is from 2.5 to 7.5 , and this is called the "aer- obic" zone. As one moves up in the scale, the individual reports $\mathrm{s} / \mathrm{he}$ is more energized, feels better about what s/he is doing, and is more efficient. The concept is similar to that used by athletes when monitoring their perceived effort. There, as individuals work harder, they burn calories and gain health benefits, but if they work too hard, they can incur serious health risks. The last category on the scale is between 7.6 and 10 , and that is called the "anaerobic" zone. Employees report being in this zone when they are overenergized, not efficient, and are, overall, not doing well (see Welbourne, 1997, for more details on the measure).

The measure was first tested within a software firm (Welbourne, 1997). The study utilized a mean of 20 weeks' worth of data to test a hypothesis on the determinants of individual performance. In a second study (Welbourne \& Felton, 1998), the measure was used as an organization went through its initial public offering (IPO). In this study, the organization, rather than the individual, was the unit of analysis. The study examined how the measure of energy changed as the organization experienced a significant organizational change event (the IPO). Therefore, although limited, there is some evidence that the measure is related to performance metrics that we would suspect should be linked if the question assessed motivation or energy at work.

For purposes of our study, we use the same 0 to 10 scale, asking the question of employees in several organizations on a weekly or biweekly basis. The data are obtained from two groups. The first study is conducted with a call center that has close to 5,000 employees. The second study is a multi-organization study (primarily smaller firms) using individual-level data collected on a weekly or biweekly basis.

\section{Study 1: Within-Company Analysis}

Due to problems in obtaining comparable performance data in the various companies studied, we chose only one organization for the test of Hypothesis 1. The establishment, a division of a Fortune 100 organization, is a call center located in the United States. The 
dependent variables collected include voluntary turnover during a six-month period starting with the first survey, ${ }^{4}$ as well as a performance measure provided at the end of the six months. We collected data and did the analysis with turnover because, at least from the organization's perspective, this was a key dependent variable for them. Turnover in a call center is very costly to the organization, and although everyone expects turnover to be higher than that found in other occupations, the organization's current turnover rate was causing other problems in productivity due to loss of knowledge, time for training, and more. The performance appraisal measure is an objective assessment made by the manager of the employee $(1=$ below expectations; 2 = on track; 3 = exceeds expectations; $4=$ significantly above expectations; the wording of the scale was changed in this article to protect the identity of the company). Not surprisingly, most people fall in the second and third groups.

The key independent variable is the energy measure described earlier (the 0 to 10 scale). Both the mean and standard deviation of this term were calculated for data collected over four time periods, with those periods representing the first four data collections.

Logistic regression was used for the turnover analysis, and linear regression was used for the performance data analysis. The energy measures are the independent variables, and control variables include gender (dummy-coded to indicate male), a departmental indicator (dummy-coded to indicate technical or operations unit versus staff), managerial status (dummy-coded to indicate manager), and race (dummy-coded to indicate white).

\section{Study 2: Multi-organization Study}

Data were gathered from seven organizations, ranging from small software firms $(\mathrm{n}=$ 236) to divisions of a Fortune 100 company $(\mathrm{n}=1,059)$. Data were collected either weekly or biweekly during the time period from May 1998 through May 2000. E-mail surveys with links to a proprietary software program were used to elicit responses from employees and conduct data analysis, allowing us to track responses within-person over time. For comparability, we utilize data from the first four survey periods for each company. These data are analyzed using correlation and regression analyses. Given the need to use four weeks of data, we limited the study to only those individuals who completed the survey during all four weeks. Thus, the sample, which started with 3,137 individuals, ended with 844 .

This study was used to test Hypothesis 2. The dependent variable is a self-report measure of job satisfaction that was obtained for four time periods. The average for each person's job satisfaction scores was used as the dependent variable $(1=$ very dissatisfied to 5 $=$ very satisfied).

Company codes were entered as a set of control variables (dummy coding). We also added pace and efficiency ${ }^{5}$ as control variables. The key independent variable, variation in employee energy, was developed by calculating the standard deviation of the energy scores over the four-week period of time. In addition, the average score for fourweek energy was used as a control variable.

\section{Analysis}

The descriptive statistics (means, standard deviations, and correlations) are presented in Table I. In the overall sample that combines the multiple company data sets, the average of energy for the first four weeks is positively correlated with job satisfaction (.08), with efficiency (.15), and with pace of work (.62). The standard deviation of energy, however, is correlated negatively with pace (-.09), efficiency $(-.10)$, and job satisfaction $(-.15)$.

In the within-company data set, turnover is positively correlated with both the mean on energy (.13) and with the standard deviation (.16). Thus, higher energy and higher variation are associated with higher turnover. The standard deviation of energy, however, is negatively related to the performance measurement scores (-.11) and positively related to the mean energy levels (.09).

The research design is such that we collected fewer questions more frequently (weekly) than one would traditionally do in
The data are obtained from two groups. The first study is conducted with a call center that has close to 5,000

employees. The second study is a multiorganization study (primarily smaller firms) using individual-level data collected on a weekly or biweekly basis. 
TABLE I Descriptive Statistics and Correlations

2a. Service center data, $n=4,629$

$\begin{array}{lccccccccccc} & \text { Mean } & \text { SD } & (1) & (2) & (3) & \text { (4) } & \text { (5) } & \text { (6) } & \text { (7) } & \text { (8) } & \text { (9) } \\ \text { 1. Turnover } & 0.07 & 0.25 & 1.00 & & & & & & & \\ \text { 2. Performance Appraisal } & 2.56 & 0.58 & 0.03 & 1.00 & & & & & & \\ \text { 3. Energy Average } & 5.68 & 1.47 & 0.13^{*} & 0.09 & 1.00 & & & & & \\ \text { 4. Energy SD } & 1.14 & 1.10 & 0.16^{* *} & -0.11 & -0.14^{* *} & 1.00 & & & & \\ \text { 5. White } & 0.84 & 0.37 & -0.14^{* *} & -0.03 & 0.15^{* *} & 0.10 & 1.00 & & & \\ \text { 6. Male } & 0.40 & 0.49 & -0.06 & -0.17^{* *} & 0.10^{*} & 0.02 & 0.15^{* *} & 1.00 & & \\ \text { 7. Manager } & 0.37 & 0.48 & 0.02 & 0.07 & 0.34^{* * *}-0.03 & 0.11^{*} & 0.16^{* *} & 1.00 & \\ \text { 8. Operations Dept. } & 0.72 & 0.45 & 0.02 & -0.05 & -0.20^{* * *} & 0.05 & -0.10 & -0.06 & -0.45^{* * *} & 1.00 \\ \text { 9. Technical Dept. } & 0.19 & 0.40 & -0.03 & -0.11 & 0.13^{*} & -0.07 & 0.031 & 0.18^{* * *} & 0.34^{* * *}-0.78^{* * *} & 1.00 \\ \text { 10. Staff Dept. } & 0.09 & 0.28 & 0.01 & 0.21^{* *} & 0.14^{* *} & 0.01 & 0.11^{*} & -0.16^{* *} & 0.23^{* * *}-0.50^{* * *}-0.15^{* *} & 1.00\end{array}$

2b. Multi-organization data, $n=844$ (after cases with missing data excluded)

$\begin{array}{lccccccc} & \text { Mean } & \text { SD } & (1) & (2) & \text { (3) } & \text { (4) } & \text { (5) } \\ \text { 1. Energy Average } & 5.86 & 1.89 & 1.00 & & & & \\ \text { 2. Energy SD } & 0.95 & 0.95 & -0.21^{* *} & 1.00 & & & \\ \text { 3. Pace Average } & 3.63 & 0.92 & 0.62^{* *} & -0.09^{* *} & 1.00 & & \\ \text { 4. Efficiency Average } & 3.51 & 0.77 & 0.15^{* *} & -0.10 & -0.15^{* *} & 1.00 & \\ \text { 5. Job Sat. Average } & 3.41 & 0.95 & 0.08^{* *} & -15^{* * *} & 0.14^{* *} & 0.39^{* *} & 1.00\end{array}$

Note: Descriptives and correlations for individual company dummy variables available from the authors.

an organizational survey. We did this to meet the needs of the firms with whom we were working, and we took advantage of technology that allowed us to do this (e.g., you would not do this if you were administering paper surveys). As such, we could not calculate reliability coefficients by analyzing multiple versions of questions that tap into the same construct-asking employees to respond to such weekly surveys on "company time" would be asking too much of them. However, we could assess reliability with a calculation that uses the results of an answer to the same question asked multiple weeks (e.g., retesting). Thus, we calculated a coefficient alpha for the four time periods, and the results are: .86 for the energy question, .88 for job satisfaction, .75 for pace of work, and .81 for efficiency.

\section{Hypothesis 1}

Hypothesis 1 states that variation in energy is negatively related to performance, and for this analysis, we studied the relationship of variance in energy to two performance outcomes, voluntary turnover and performance appraisal scores. Table II presents the results of a logistic regression on voluntary turnover in this establishment. Table III presents the results of a linear regression on managerial assessments of employee performance in the same establishment. In both analyses, the question we are addressing is whether variation in energy predicts performance-related outcomes.

The first block in Table II includes the control variables. The next block adds in the average energy, while the final block adds in the standard deviation of energy over the same time period. The clearest effect is that increasing the standard deviation of employee energy makes it more likely that a worker will leave the establishment. The results in Table III offer parallel but less compelling results for managerial assessment of worker performance. Overall, these data present support for Hypothesis 1, although the relationship appears stronger for termination than performance assessment. Workers may be able to continue to perform in the short term at acceptable levels, but the termination results point to more detrimental long-term effects. 
TABLE II Service Center Data: Dependent Variable-Voluntary Termination

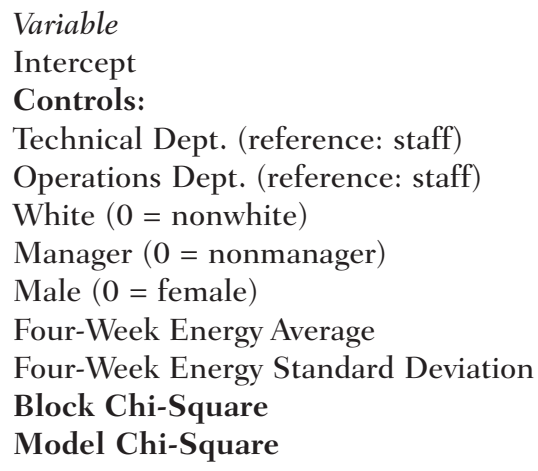

\section{Hypothesis 2}

To examine the link between energy and job satisfaction, we use the multi-organization data (Table IV). Here, we predict average job satisfaction as an outcome. Job satisfaction was assessed during the same time period the energy question was asked. We again begin by controlling for any superfluous company effects using company dummy indicators in the first block. It is apparent that the companies differ in the average level of job satisfaction (measured on a five-point scale).
In the second block, we add in the pace and efficiency measures, which were metrics that we collected at all organizations; thus, we could use these as additional control variables for the analysis. The only two statistically significant effects are for variation in energy and the average efficiency. As one's general sense of efficiency increases, so does one's job satisfaction. As variation in energy increases, satisfaction decreases. Thus, Hypothesis 2 receives support from this multi-organization analysis.

TABLE III Energy-Performance Scale Analysis: Dependent Variable-Performance Appraisal Scores

Variable

Intercept

Controls:

Operations Dept. (reference: staff)

Technical Dept. (reference: staff)

White $(0=$ nonwhite $)$

Manager $(0=$ nonmanager $)$

Male $(0$ female $)$

Independent Variable

Energy Standard Deviation: 4 Weeks $\mathbf{R}^{2}$

Adj. $\mathbf{R}^{2}$

$\mathbf{R}^{2}$ Change
Model 1

\begin{tabular}{cc}
\hline Block 1 & Block 2 \\
B (s.e. $)$ & B(s.e) \\
$2.90(0.17)^{* *}$ & $2.97(0.17)^{* * *}$ \\
& $-0.26(0.13)^{*}$ \\
$-0.26(0.13)^{*}$ & $-0.39(0.15)^{* *}$ \\
$-0.37(0.15)^{*}$ & $-0.06(0.12)$ \\
$-0.07(0.12)$ & $0.09(0.09$ \\
$0.09(0.09)$ & $-0.14(0.08) !$ \\
$-0.14(0.08) !$ & $-0.07(0.04) !$ \\
& $\mathbf{0 . 0 8}{ }^{* *}$ \\
\hline $\mathbf{0 . 0 7 *}$ & $\mathbf{0 . 0 5}$ \\
$\mathbf{0 . 0 4}$ & $\mathbf{0 . 0 2 !}$ \\
$\mathbf{0 . 0 7}$ & -
\end{tabular}

$! \mathrm{p}<.10,{ }^{*} \mathrm{p}<.05,{ }^{* *} \mathrm{p}<.01,{ }^{* * *} \mathrm{p}<.001$. 
TABLE IV Energy Level and Job Satisfaction: Multi-organization Data-Dependent Variable: Average Job Satisfaction

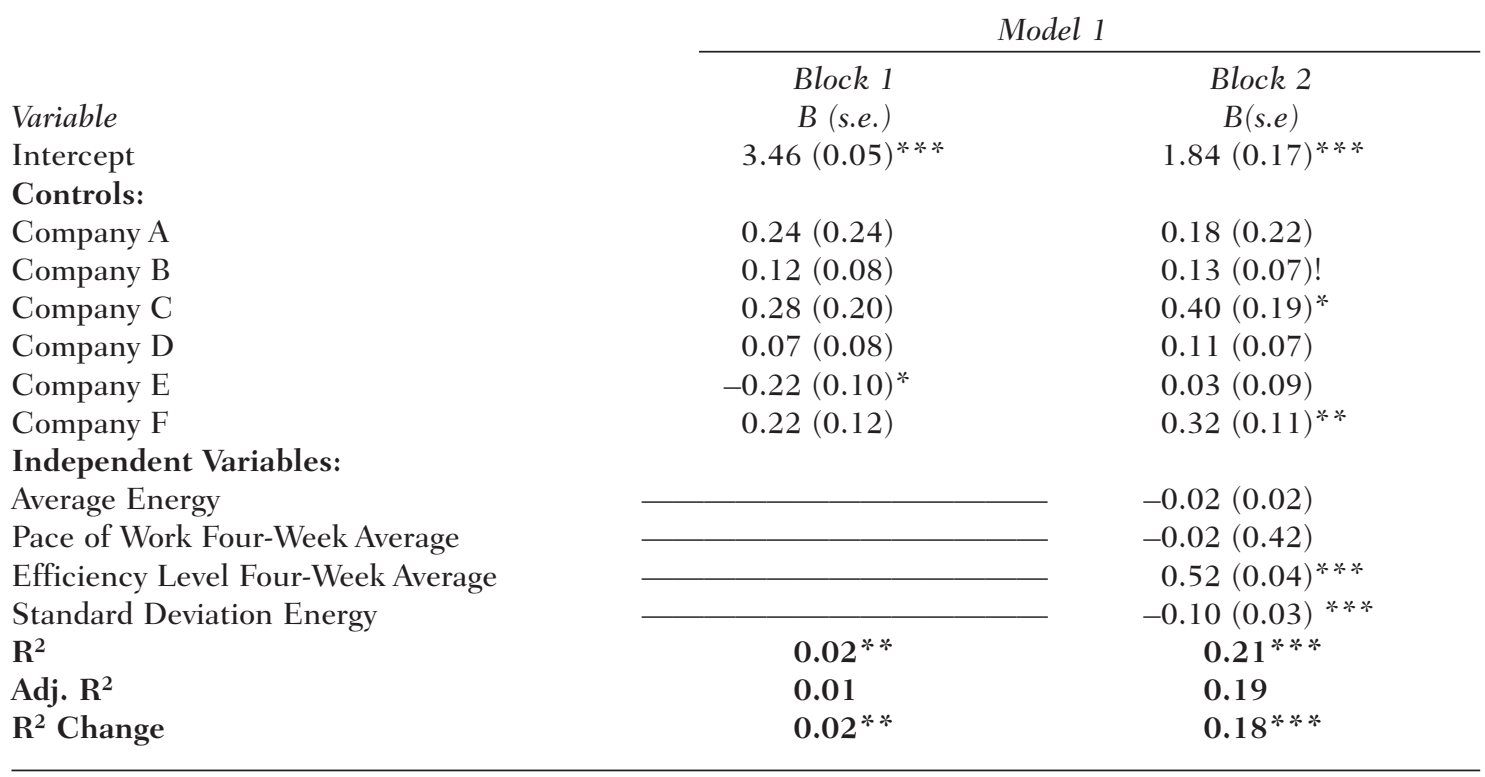

$! \mathrm{p}<.10,{ }^{*} \mathrm{p}<.05,{ }^{* *} \mathrm{p}<.01,{ }^{* * *} \mathrm{p}<.001$

\section{Discussion}

Our search for a new way to approach motivation at work led us to consider the sports physiology literature. The analogy we drew, based on the key findings of that area of research, proved useful for examining the link between motivation, directed human energy, and employee performance outcomes (including turnover). We show there is a conceptual bridge between the understanding of the human body from a physiological viewpoint and ways of thinking about the social behaviors of human beings, particularly in the workplace.

Much like physical training helps the body adapt to the exertion of exercise, managers can help employees adapt to working at a higher stress level. As with physical training, this adaptation can only be pushed so far. A runner cannot sprint a marathon and remain healthy any more than a worker can sustain burnout levels and remain energized. But there is a zone within which people can be pushed to perform more effectively at an increased workload. Furthermore, training implies that the stressors are increased in a steady fashion so that the body has time to adapt. The "weekend warrior" effect can occur in the workplace, when people who are not used to stress are suddenly subject to very high levels. This type of variation in energy level leads to observable performance loss in the workplace, specifically showing up in an increased risk of turnover and lower objective performance. Similarly, variation in the energy level is associated with lower job satisfaction because of the accompanying changes in the perceived difficulty of accomplishing one's tasks.

\section{Implications for Research}

Energy contextualizes a person's effort such that the link between motivation and performance outcomes becomes relative to the capacities of that individual; the same amount of motivational technology applied to two individuals may result in the same subjective gain in performance, but this will not be reflected in similar objective performance improvements. ${ }^{6}$ Motivation research has to focus on more than the link between the perceptions of managers and objective performance gains. 
Finally, having personally experienced the detrimental effects of overtraining ourselves, we suggest that the motivation literature must place more analytic emphasis on the potential for "overmotivating" employees over the long term. While early organizational theorists (such as Marx or Taylor) focused on the way workers resist managerial demands for more output, and though many criticize American workers for their sloth, we suggest there are many people out there working very hard (cf. Hochschild, 1997; Schor, 1993). Ultimately, though, both sides of the motivation coin (under- and over-) are equally important from a research stance.

We suggest that the implications of our work reach beyond the motivation literature. Although the notion that there are limits on gains from pressing further along a path is not new to the social sciences (human capital explanations of the age effect on wages and the Laffer curve are two examples), we do believe the emphasis on the limits introduced by the human organism need to be better studied in organizational settings. We note that even this insight is not new to the social sciences; indeed, it is one of the cornerstones of Taylor's scientific management approach. However, biology has advanced a lot from Taylor's day. Organizational and individual performance are more than states of mind.

Another interesting application may be using the energy work to understand employee engagement. As employee engagement seems to be fast becoming a subject of interest to many consultants and HR managers, application of motivation and energy theory may help bring some additional theoretical perspectives to the work.

\section{Limitations}

Although the research is strengthened by having multiple sites and multiple time periods of study, these same factors also present limitations for our work. It was difficult to find comparable performance outcome measures (thus, performance was examined in only one organization), and control variables were not equally available at all sites. In addition, the frequent nature of our data collection and extensive reliance on open- ended comment data meant that our ability to add supplemental questions was limited. Future research would benefit from including multiple measures of motivation and the predictors and outcomes of energy so that a more thorough nomological network could be established and explored over time and across organization types.

Additionally, many of the items used in the studies were collected from individual employees. For example, the analysis of energy and satisfaction used data collected from the same respondent. Thus, errors associated with response bias must be considered. However, our ability to ask questions in multiple time periods may have helped minimize such errors.

\section{Implications for Practitioners}

The results of this initial set of studies show that energy can be predictive of performance, including turnover and employee job satisfaction. However, the stories behind "how" the organizations used the data, took action based on their information, and then made changes in key outcome variables (such as turnover, customer service scores, etc.) provide just as much insight as do the statistical analyses. Thus, in this section, we will review short summaries of some of the managerial experiences in the firms included in the overall research project.

First, we will relate the details behind how turnover was reduced in the company represented in the turnover analysis. A reduction in turnover of $26 \%$ occurred over a six-month period, and the actions taken by management and the HRM department were directly related to these changes in turnover. The assumption of the management team prior to the data collection effort was that serious changes in pay structure and job design were needed in order to make any significant changes in turnover. However, once the data were collected, in addition to analyzing the energy metric, a content analysis of comments was conducted. This analysis of the comments showed that high variance in the energy scores was associated with two types of comments: (1) dress code and (2) organization pride. ...the stories behind "how" the organizations used the data, took action based on their information, and then made changes in key outcome variables (such as turnover, customer service scores, etc.) provide just as much insight as do the statistical analyses. 
This

intervention of simply communicating back to employees about the fact that they read their data was enough to optimize employee energy levels.
The dress code comments were either people complaining about "sloppy" dress by a segment of the population (basically, more senior employees were complaining about what they perceived to be inappropriate dress by the more junior hires). Additionally, the more junior employees complained that the dress code was too rigid (they worked in a warm climate and wanted to wear shorter shorts, sandals, etc.). After reviewing the comments with the management team, we found out that the leaders in the organization knew about the problem, but no one had really wanted to take a stand and deal with it. It was one of those divisive issues that had been set aside because any answer would result in some subgroup being unhappy with the decision. However, when the bulk of comments were analyzed and trended, the management team decided it was finally time to deal with the problem.

The second major issue that arose from an analysis of the comment data was associated with the name of the company and associated materials representing the name of the company after a merger. Employees commented on being demotivated by the fact that their "new" postmerger company name (signs, letterhead, etc.) had not changed yet. In particular, a sign on the front of the building simply had a cover over it (no name-just a blank space). Employees said they felt this signal to the world was a sign their company was going out of business, that no one recognized their past efforts, and that the new company did not take as much pride in this particular site.

The results of the data analyses were reviewed by the senior management team, and they revised the dress code and communicated it to employees, and the sign outside the building was finalized (with the name of the new company). After tackling those two issues and communicating to employees that they responded to their concerns, turnover started to decrease. Within six months, the turnover rate at this firm went down by $26 \%$. During this time, there were no changes in pay and no changes in job design. The changes that were made were fairly small and inexpensive.
A second company in the sample was in the process of going through a merger. The employee comments were focused on their concerns about the state of the company after the merger. Rather than only having the most senior executives respond to the employee data, all managers were given access to their own scores and comment data. As a result, the reports and actions associated with their data were reviewed in the weekly management meeting. Unfortunately, there was little action managers could take in response to the comments and data. Management at this site did not have full information about the postmerger plans; thus, they were as frustrated as the employees. However, the management team decided that after each weekly management meeting, they would review the results of the meeting and the survey data with their own employees. This intervention of simply communicating back to employees about the fact that they read their data was enough to optimize employee energy levels. After about six months of data collection and merger negotiations, the merger itself was called off. As a result of managing the communications during this period of time, the site in question retained very high levels of productivity. The senior executive of the site was promoted, and the group fared well in the subsequent reorganization.

The lessons learned from the managers participating in the research study are focused on what you can do to affect employee energy. How can a manager help his/her employees stay "in the zone?" What we learned from following these organizations and managers over time is that the intervention can be quite simple. Communication alone was a powerful tool in helping employees deal with stress (see the merger company example above). Additionally, we learned the things that are affecting energy negatively are often simple, and they are sometimes not what we, the HR team or consultants, think should be affecting the employees. When the data from employees were analyzed, the management teams quickly found that some fairly simple interventions could be used to help employees. However, the interventions were continu- 
ous versus being point-in-time events. Perhaps that's why personal coaching is becoming so popular for people who exercise as well as for senior executives. There is something to be said for frequent measurement and communications.

The role of the human resource executive in the management and leadership development process can be similar to the role of the personal coach of the athlete. Data alone is not enough to make the athlete successful; the athlete needs someone who can help him/her interpret the data and develop an action strategy based on that data. If HR executives can help leaders create their own personal action strategies, then the role of
HR evolves into one that helps all employees optimize energy at work.

We learned from this series of studies that the intervention was as powerful as the energy metric. Energy is a concept that is well grounded in theory, that can be measured, and for which we think management research can provide valuable insights to managers. However, the process of changing research from a one-time event to a continuous process also has important implications for organizations. Our own work continues to focus on the measurement and the intervention, and we expect to learn more about how to energize employees and leaders as the research continues.

Theresa M. Welbourne, PhD, is the founder, president, and CEO of eePulse, Inc., a technology and management research company delivering proprietary Web-based leadership tools that improve firm performance through measurement and communication with stakeholders. She also is an adjunct professor of executive education at the University of Michigan Business School and the editor-in-chief of this journal. She has over 25 years' experience working in the field of HRM, in academic, consulting, and executive management roles. Dr. Welbourne's expertise is in the area of strategic HRM and HR leadership in high-growth and high-change organizations. Her particular focus is on understanding how various human resource, communication, and leadership strategies can harness employee and customer energy to improve firm performance.

STEven B. Andrews, PhD, is a former professor of sociology who left to work in small start-up tech firms. He is also a three-hour marathoner.

Alice O. Andrews, PhD, is vice president of operations at Leadership in Medicine, Inc. Prior to this position, she was vice president of research and learning at eePulse, Inc., and an assistant professor at the Owen Graduate School of Management at Vanderbilt University. Research for this article inspired her recent participation in a 210mile running relay across New Hampshire.

\section{NOTES}

1. As will become apparent later in this article, there are two ways in which variation appears in training, one of which is detrimental and the other beneficial.

2. For an overview of the exercise physiology literature, see the Report of the Surgeon General (1999).
3. Use of this metric requires written permission from the author.

4. Involuntary terminations were excluded from the analysis, since they arise because of a different process. However, the results did not change with involuntary terminations included.

5. Pace and efficiency, also one-item questions, were assessed for four weeks in each organization. Employees were asked to rate their pace 
at work with a five-point Likert scale ranging from very slow to very fast, and efficiency at work, also using a five-point scale ranging from very low to very high. The average scores over the four weeks were used for the analysis.

6. Think of going for a jog with a world-class marathoner. You may both equally benefit from the application of some motivational tool, but that hardly means the average person could actually "jog" alongside the marathoner. Likewise, the gain would not necessarily be the same (the marathoner is near her/his limits already, so s/he may show little objective improvement in terms of magnitude change.

\section{REFERENCES}

Ambrose, M. L., \& Kulik, C.T. (1999). Old friends, new faces: Motivation research in the 1990s. Yearly Review of Management of the Journal of Management, 25, 231-292.

Burfoot, A. (Ed.). (1997). Runner's World complete book of running: Everything you need to know to run for fun, fitness, and competition. Emmaus, PA: Rodale Press.

Csikszentmihalyi, M. (1991). Flow: The psychology of optimal experience. London: HarperCollins.

Gilbert, B., \& Jamison, S. (1994). Winning ugly: Mental warfare in tennis-Lessons from a master. New York: Simon \& Schuster.

Glover, B., \& Glover, S.F. (1999). The competitive runner's handbook: The bestselling guide to running $5 \mathrm{Ks}$ through marathons (Revised Ed.). New York: Penguin.

Hargrove, R. (1995). Masterful coaching: Extraordinary results by impacting people and the way they think and work together. San Francisco: Jossey-Bass.

Hochschild, A. (1997). The time bind: When work becomes home and home becomes work. New York: Henry Holt.

Kinlaw, D. C. (1999). Coaching for commitment:
Interpersonal strategies for obtaining superior performance from individuals and teams. San Francisco: Jossey-Bass.

Landy, F. J., \& Becker, W. S. (1987). Motivation theory reconsidered. Research in Organizational Behavior, 9, 1-38.

Lawler, E. E., III. (1973). Motivation in work organizations. Pacific Grove, CA: Brooks/Cole.

Leifer, E. M. (1988). Trails of involvement: Evidence for local games. Sociological Forum, 3(4), 499-524.

Noakes, T. (1991). Lore of running (3rd ed.). New York: Leisure Press.

Perry, J. M., \& Jamison, S. (1997). In the zone: Achieving optimal performance in business-as in sports. Berkeley, CA: Contemporary Press.

Pinder, C. C. (1984). Work motivation. Glenview, IL: Pearson Scott Foresman.

Report of the Surgeon General. (1999). Physical activity and health. Retrieved March 31, 2000, from http://www.cdc.gov/nccdphp/sgr/sgr/htm

Rosenbaum, J. (1979). Tournament mobility: Career patterns in a corporation. Administrative Science Quarterly, 29, 220-241.

Schor, J. (1993). The overworked American: The unexpected decline of leisure. New York: Basic Books.

Shula, D., Blanchard, K., \& Cruderman, L. (1995). Everyone's a coach: You can inspire anyone to be a winner. Grand Rapids, MI: Zondervan.

Welbourne, T. M. (1997). Valuing employees: A success strategy for fast growth firms and fast paced individuals. In P. D. Reynolds, W. D. Bygrave, P. Davidsson, W. B. Gartner, C. M. Mason, \& P. P. McDougall (Eds.), Frontiers of entrepreneurship research 1997 (pp. 17-31). Babson Park, MA: Center for Entrepreneurship Research.

Welbourne, T. M., \& Felton, R. W. (1998). Improving technology-based change processes: A case study of Indus international. Journal of Strategic Performance Measurement, 2(2), 22-25. 